\title{
Green Synthesis and Antibacterial Properties of Silver Nanoparticles Using Sudanese Azadirachta indica Leaves Extract
}

\author{
Ayat Ahmed Alrasheid ${ }^{1, *}$, Sahar Hussein Eltilib ${ }^{2}$, Shimaa Abdel Rahman Ahmed ${ }^{3}$, \\ Alaa Abdulmoneim Mohamed ${ }^{4}$, Hiba Abbas Widatalla ${ }^{2}$, Layla Fathi Yassin ${ }^{3}$, Maida Musa Ali ${ }^{3}$, \\ Marvit Osman Widdatallh ${ }^{2}$ \\ ${ }^{1}$ Department of Pharmacognosy, Faculty of Pharmacy, University of Medical Sciences and Technology, Khartoum, Sudan \\ ${ }^{2}$ Department of Pharmacology, Faculty of Pharmacy, University of Medical Sciences and Technology, Khartoum, Sudan \\ ${ }^{3}$ Department of Pharmaceutical Analysis, Faculty of Pharmacy, University of Medical Sciences and Technology, Khartoum, Sudan \\ ${ }^{4}$ Department of Clinical Pharmacy, Faculty of Pharmacy, University of Medical Sciences and Technology, Khartoum, Sudan \\ Email address: \\ ayatwarag@yahoo.com (A. A. Alrasheid), Sahareltilib11@gmail.com (S. H. Eltilib), Shimagggyas@gmail.com (S. A. R. Ahmed) \\ ${ }^{*}$ Corresponding author
}

\section{To cite this article:}

Ayat Ahmed Alrasheid, Sahar Hussein Eltilib, Shimaa Abdel Rahman Ahmed, Alaa Abdulmoneim Mohamed, Hiba Abbas Widatalla, Layla Fathi Yassin, Maida Musa Ali, Marvit Osman Widdatallh. Green Synthesis and Antibacterial Properties of Silver Nanoparticles Using Sudanese Azadirachta indica Leaves Extract. Science Research. Vol. 8, No. 1, 2020, pp. 14-19. doi: 10.11648/j.sr.20200801.13

Received: January 26, 2020; Accepted: February 19, 2020; Published: April 28, 2020

\begin{abstract}
Nanoparticles have emerged as a key player in modern medicine and involved in drug delivery, it can be manufactured using various approaches including chemical, physical, and biological methods. Nanoparticles are generally characterized by their size, morphology and surface charge using advanced microscopic techniques such as SEM and TEM. This study was aimed for synthesis and characterization of silver nanoparticle and to detect their antibacterial activity using Azadirachta indica (Neem) leaves extract. The results showed a visible change of colour after the addition of Neem leaf extract to $\mathrm{AgNO}_{3}$ solution to dark brown which indicates the formation of silver nanoparticle. UV spectrophotometer showed absorbance peak in range of 390-700 nm, the result revealed the highest peak showed by concentration $1 \mathrm{ml}$ at $428.80 \mathrm{~nm}$. SEM and XRD analysis were used to characterize synthesize silver nanoparticles. The antibacterial activity against Gram positive Staphylococcus aureus and Gram negative Escherichia coli and Klebsiella spp Microorganisms was carried out using disc diffusion method, the results showed that the highest activity was $14 \mathrm{~mm}$ against $S$. aureus. A. indica silver nanoparticles can be used as a new nano drug in formulation and delivery. The synthesized silver nanoparticles are extremely important in various areas of life and are widely used for the benefit of human being.
\end{abstract}

Keywords: Green Synthesis, Silver Nanoparticles, Azadirachta indica, SEM, XRD, Antibacterial Properties, Sudan

\section{Introduction}

Nanoparticles have unique chemical, physical and biological properties, and are therefore used in various fields such as business, therapies, electronics, cosmetics; chemical catalysis and drug delivery [1]. Metal nanoparticles have attracted a lot of attention in recent years due to their unique properties that differ from bulk materials. These particles have gained importance in recent years due to their wide application in a number of processes such as agriculture, cosmetics, health care, delivery of drugs or genes, medical devices, biosensors and chemical catalysis [2]. AgNPs have the ability to work as therapies with diverse clinical and pharmacy properties. It can be used in wide applications, including anti-cancer or bactericidal agents during surgery. In this way, green synthesis of AgNPs as new therapeutic powers will be important in various biomedical applications [3]. Green method of NP synthesis is used with plant extracts, 
bacteria, actinomycetes, fungi, and enzymes due to their environmentally friendly nature and bio-compatibility $[4,5]$. The main compounds present in plant extracts are glycosides, alkaloids, phenols, amines and terpenoids that convert silver ions into nanoparticles of silver [4, 6]. Thus, the leaves, bark, flowers and seed extract from plants containing this chemical compounds are used as a source for reducing factors. Azadirachta indica belongs to family Meliaceae, it is an important medicinal plant in Sudan. Traditionally, Sudanese have used $A$. indica leaf to treat many diseases, and many researchers have reported pharmacological studies of $A$. indica including; anti-malarial activity, wound, mollucicidal, antimicrobial activity...etc [7]. The present study reports the synthesis and characterization of silver nanoparticle from $A$. indica leaves extract and their antimicrobial activity.

\section{Materials and Methods}

\subsection{Materials}

\subsubsection{Plant Material}

Azadirachta indica leaves used in this study was collected directly from the field from the University of Medical Sciences and Technology, Khartoum, Sudan. The specimen has been deposited in Pharmacognosy department.

\subsubsection{Chemicals}

Silver nitrate $\left(\mathrm{AgNO}_{3} ; 99.8 \%\right)$ was purchased from SigmaAldrich Co. (St Louis, MO, USA). All general reagents used in this study were purchased from British Drug Houses (BDH), England. Sigma Chemical Company, USA.

\subsubsection{Bacterial Strains}

Isolated Gram positive Staphylococcus aureus and Gram negative Escherichia coli and Klebsiella spp were used in this study. The tested organisms were obtained from Department of Microbiology, Medical Laboratory Sciences, University of Medical Sciences and Technology.

\subsection{Methods}

\subsubsection{Preparation of Plant Extract}

About 20 grams of fresh clean leaves of Azadirachta indica were chopped into small pieces. The sample was soaked in deionized water $(100 \mathrm{ml})$ and boiled in water path for 45 minutes, the aqueous solution obtained after reflux was filtered by whattman paper number 4 .

\subsubsection{Synthesis of Silver Nanoparticles}

For the synthesis of the silver nano particles, a certain volume of the Neem leaves extract (1, 2, 3, 4 and $5 \mathrm{ml}$ ) was added to the $\mathrm{AgNO}_{3}$ solution and the volume was adjusted to $10 \mathrm{ml}$ with $1 \mathrm{mM} \mathrm{AgNO}_{3}$ prepared as starting material for synthesis of silver nanoparticles in a test tubes, then the reaction mixture in a test tubes were incubated at room temperature for 2 to 4 hours. Blank solutions were prepared in the same manner without addition of silver nitrate solution. Separation of nanoparticles pellet was done by centrifugation (at $6000 \mathrm{rpm}$ for 20min) of reaction mixture and wash of pellet by deionized water and acetone (1:1). This process was repeated 3 times in order to get a pure silver nanoparticle pellet, then allowed to dry at room temperature and stored in clean dry container for further analysis [8].

\subsubsection{Characterization of Silver Nanoparticles}

\section{(i). Ultraviolet (UV)/Vis Spectroscopy}

The formation of silver nanoparticles was evaluated using UV spectrophotometer (Shimadzue). All reaction mixture solutions were scanned in a range of 390-800 $\mathrm{nm}$. The nanoparticle formation was ascertained by recording UVvisible spectra (double beam spectrophotometer 2202Systronics).

\section{(ii). SEM analysis}

SEM analysis was done using Scanning electron Microscopic (SEM) (TESCAN MIRA). Thin films of samples were prepared on a carbon coated copper grid by just dropping a very small amount of sample on the grid.

\section{(iii). X-Ray Diffraction Analysis}

The silver nanoparticle solution was centrifuged at 2500 rpm for $20 \mathrm{~min}$. The pellet was washed three times with 20 $\mathrm{ml}$ of deionized water. The dried powder of silver nanoparticles was collected for the determination of formation of silver nanoparticles (XRD-7000s/7000L Shimedazu).

\subsubsection{Antibacterial Assay \\ Disc diffusion method}

The antibacterial assay was done on human pathogenic Staphylococcus aureus, Escherichia coli and Klebsiella spp using standard disc diffusion method [9]. The bacterial stock suspensions were streaked on Mueller Hinton agar medium plates using sterile cotton swab. Sterile paper discs of $6 \mathrm{~mm}$ diameter saturated with different concentrations of Neem silver nanoparticles $(20,10$ and $5 \mathrm{mg} / \mathrm{ml})$ placed in each plate and incubated at room temperature for 24 hour. DMSO used as a control negative and Ciprofloxacin used as a control positive. The antibacterial activity was evaluated by measuring the zone of growth inhibition against the tested gram positive and gram negative bacteria.

\section{Results and Discussion}

\subsection{Characterization of NPs}

\subsubsection{Synthesis of Silver Nanoparticles}

Azadirachta indica leaves were used to produce silver nanoparticles and the reduction of silver ions into silver particles during exposure to the plant extract was followed by colour change. In all experiments, addition of plant extract of $A$. indica into the tubes containing aqueous solution of silver nitrate led to the change in the colour of solution from colour less to yellowish to reddish brown (Figure 1) within reaction duration due to excitation of surface plasmon vibrations in silver nanoparticles [10]. 


\subsubsection{Analysis of Silver Nanoparticles by $U V$-visible Spectroscopy}

The UV absorption spectrum of silver nanoparticles from $A$. indica leaves extract of different concentrations showed in Table 1. The peak occurs at $428.80 \mathrm{~nm}(\lambda$ max $)$ which corresponds to the best absorbance of silver nanoparticles.
Highest peak has been attributed to the excitation of surface plasmon resonance (SPR) of Ag NPs (Figure 2). Profile of the UV-Vis spectrum depends on the concentration of substrate and silver ions. The intensity of peak decrease with increase of concentration, the result revealed the highest peak showed by concentration $1 \mathrm{ml}$.

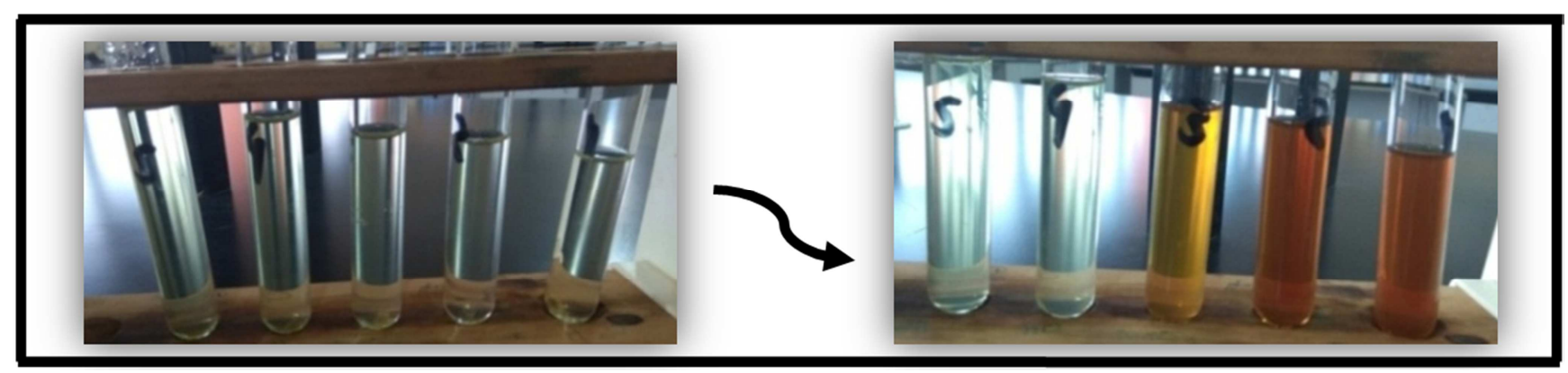

Figure 1. Colour Change in the five concentrations of A. indica extract with silver solution.

Table 1. UV spectrum of sliver nanoparticles formed from A. indica leaves extract.

\begin{tabular}{llllll}
\hline Concentration & $\mathbf{1 ~} \mathbf{~ l}$ & $\mathbf{2} \mathbf{~ m l}$ & $\mathbf{3} \mathbf{~ m l}$ & $\mathbf{4} \mathbf{~ m l}$ & $\mathbf{5} \mathbf{~ m l}$ \\
\hline Wave length & 428.80 & 424.00 & 416.20 & 395.40 & 397.40 \\
Absorbance & 1.165 & 1.002 & 0.751 & 0.542 & 0.529 \\
\hline
\end{tabular}

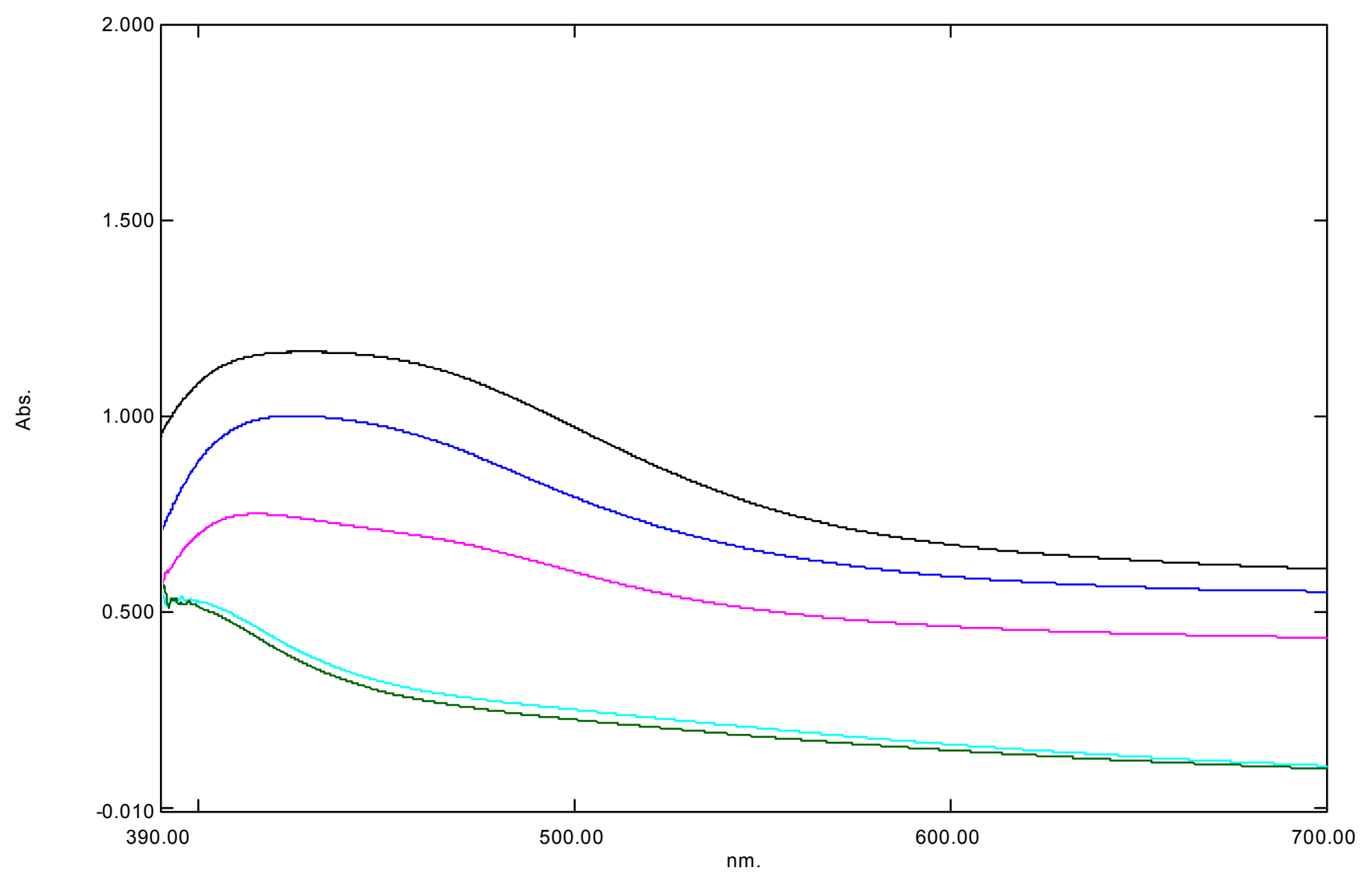

Figure 2. UV spectrum of sliver nanoparticles formed from A. indica leaves extract.

\subsubsection{SEM Analysis}

The surface morphological and nanostructural studies using SEM are shown in Figure 3. The topology and size were also confirmed by SEM images showing the presence of small and uniformly spherical shaped Ag NPs with smooth surface and very narrow distribution range of $13 \mathrm{~nm}, 17.61$ $\mathrm{nm}$ and $27 \mathrm{~nm}$. 

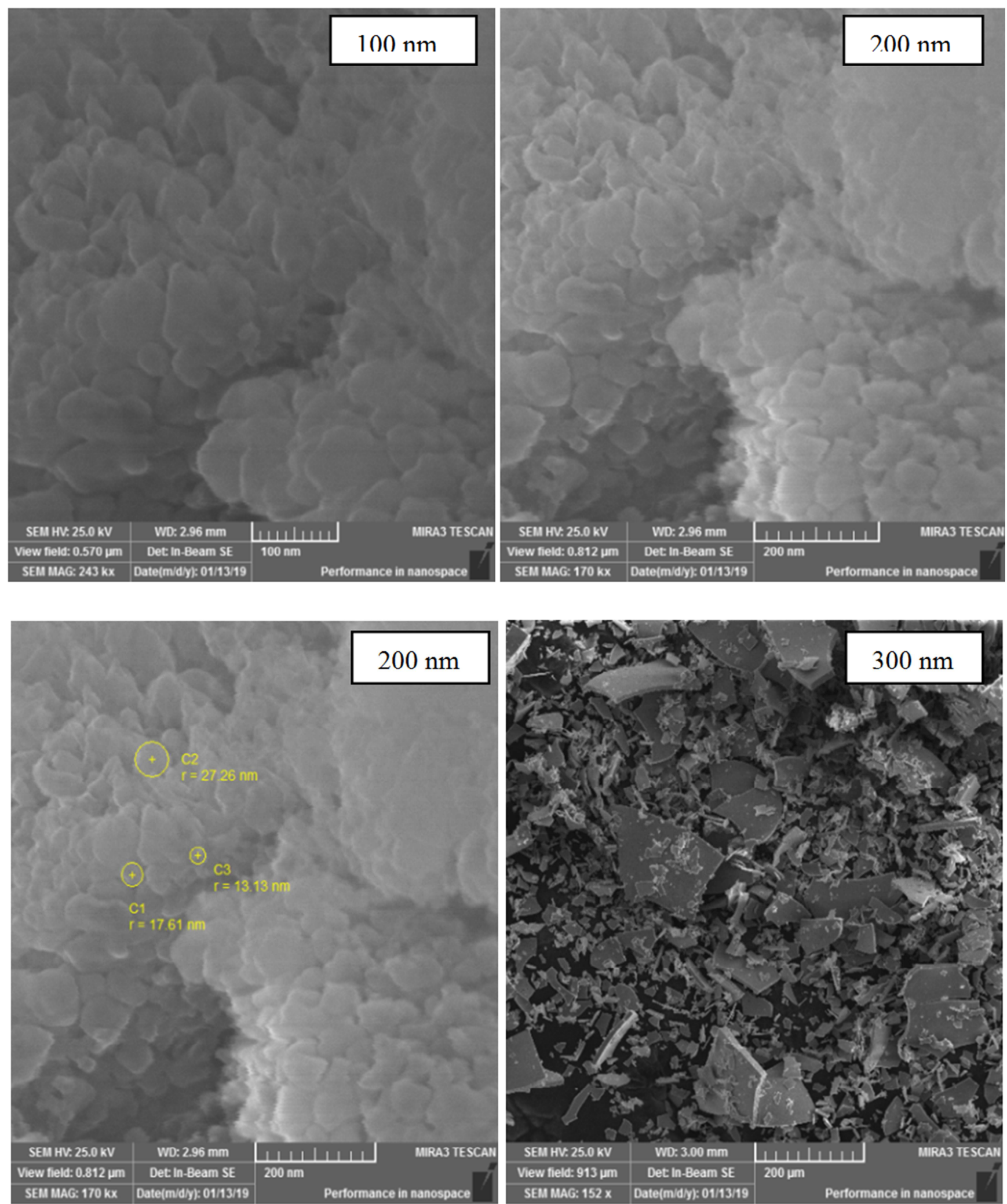

Figure 3. SEM analysis of silver nanoparticles.

\subsubsection{XRD Analysis}

$\mathrm{X}$-ray diffraction (XRD) is a commonly used method to determine the crystal structures of nanoparticles. The average size was $(44.99 \mathrm{~nm})$ ranging between 10 and $80.01 \mathrm{~nm}$ (Figure 4). 


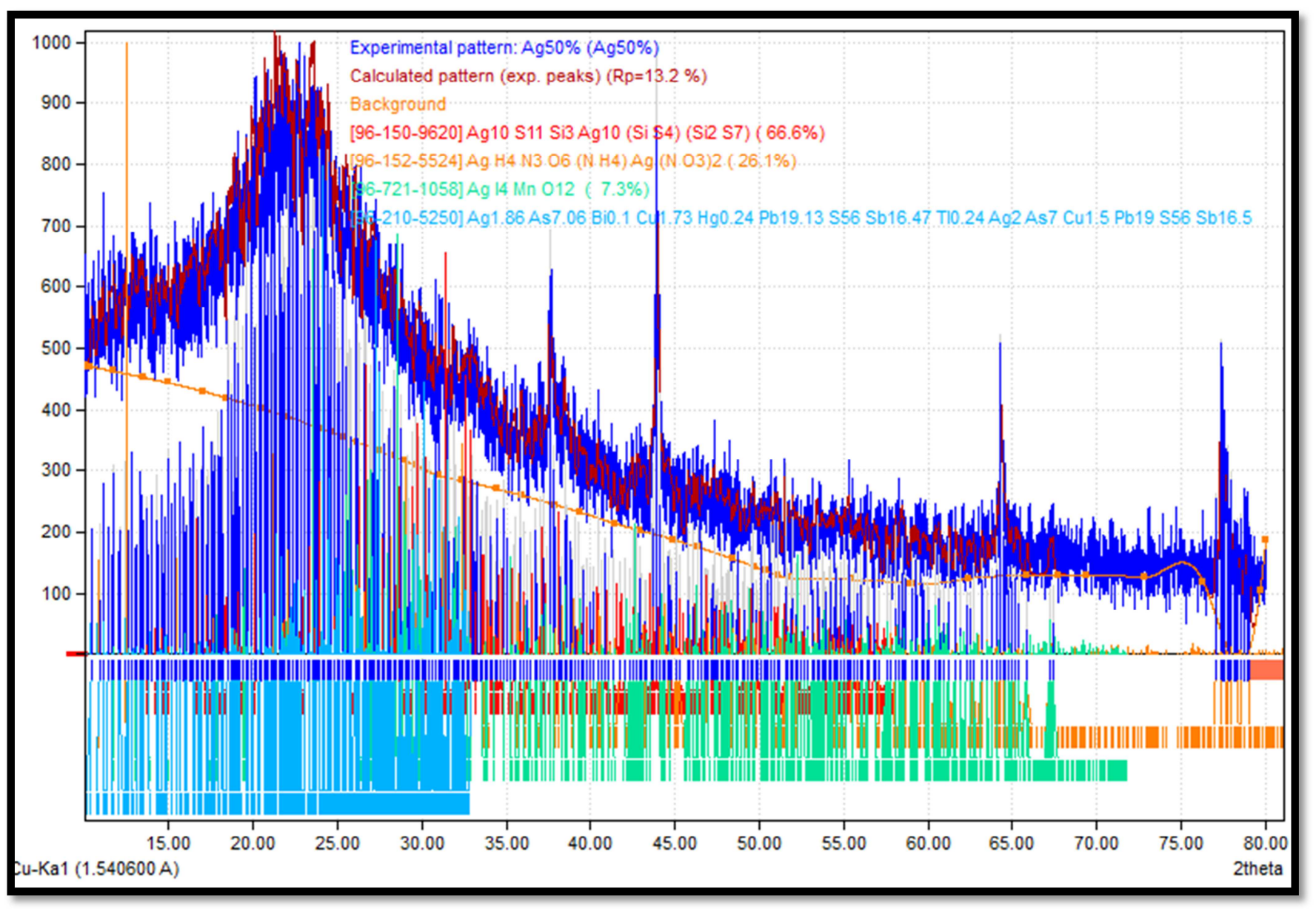

Figure 4. XRD analysis of silver nanoparticles.

\subsection{Antibacterial Activity}

Table 2. Antibacterial activity of silver nanoparticles against three bacteria species.

\begin{tabular}{llll}
\hline \multirow{2}{*}{ Concentration } & \multicolumn{3}{l}{ Diameter of Inhibition Zone $(\mathbf{m m})$} \\
\cline { 2 - 4 } & Klebsiella spp. & E. coli & S. aureus \\
\hline $20 \mathrm{mg} / \mathrm{ml}$ & 10 & 8 & 14 \\
$10 \mathrm{mg} / \mathrm{ml}$ & 7 & 6 & 8 \\
$5 \mathrm{mg} / \mathrm{ml}$ & 6 & 6 & 7 \\
Ciprofloxacin & 26 & 18 & 31 \\
\hline
\end{tabular}

The results of antibacterial activity of silver nanoparticles with different concentrations against three microorganisms are presented in Table 2 . The activity of silver nanoparticle was concentration dependant. The highest activity of silver nanoparticles showed against $S$. aureus (14mm). Nanotechnology is expected to open some new aspects to fight and prevent diseases using atomic scale tailoring of materials. The ability to uncover the structure and function of biosystems at the nanoscale stimulates research leading to improvement in biology, biotechnology, medicine and healthcare. Vijayakumar et al [11] reported silver nanoparticles synthesized Asteraceae have great susceptibility to different microbes. Other study showed that the synthesis of silver nanoparticles using plant extract gave good antimicrobial activity against Escherichia coli, Proteus mirabilis and Shigella flexneri. Silver nanoparticles are reported to possess anti-fungal, anti-inflammatory, anti-viral, anti-angiogenesis and antiplatelet activity besides effective antimicrobial agent against various pathogenic microorganisms [12].

\section{Conclusion}

In this study, Azadirachta indica conjugated silver nanoparticles were synthesized using their leaves extract. The synthesized nanoparticles were characterized by using UVVis spectrum, SEM and XRD. The formation of NPs was observed by visible colour change from yellow to brown and confirmed by UV visible analysis. Crystalline nature of the nanoparticles is evident from sharp peaks in the XRD pattern. The AgNPs displayed antibacterial activity against E. coli, Klebsiella spp and $S$. aureus. The results showed that $A$. indica plays an important role in the reduction and stabilization of silver to silver nanoparticles and further investigations need to develop new formula.

\section{Conflict of Interests}

Authors declare no conflict of interests. 


\section{Acknowledgements}

The present work is the part of devoted interdepartamental on-going research in the Faculty of Pharmacy, University of Medical Sciences and Technology. The authors are grateful to the General Administration of Forensic Evidence, Police Forensic Labs, Chemistry Department, Khartoum, Sudan, and Department of Pharmaceutical Analysis, Faculty of Pharmacy, UMST for their assistance and support.

\section{References}

[1] Sriram, M. I., Kalishwaralal, K., Barathmanikanth, S and Gurunathani, S. (2012). Size-based cytotoxicity of silver nanoparticles in bovine retinal endothelial cells. Nanosci Methods; 1 (1): 56-77.

[2] Riley, M. A., Robinson, S. M., Roy, C. M., Dennis, M., Liu, V., Dorit, R. L. (2012). Resistance is futile: the bacteriocin model for addressing the antibiotic resistance challenge. Biochem Soc Trans. 40 (6): 1438-1442.

[3] Ovais, M., Khalil, A. T., Raza, A., Khan, M. A., Ahmad, I., Islam, N. U., Saravanan, M., Ubaid, M. F., Ali, M and Shinwari, Z. K. (2016). Green synthesis of silver nanoparticles via plant extracts: beginning a new era in cancer theranostics. Nanomedicine; 12 (23): 3157-77.

[4] Khan, M., Adil, S. F., Musarrat, J., Al-Khedhairy, A., AlWarthan, A., HSiddiqui, M. R., Rafiq, M and Alkhathlan, H. (2014). Antibacterial properties of silver nanoparticles synthesized using Pulicaria glutinosa plant extract as a green bioreductant, Mujeeb Khan Shams Tabrez Khan, International Journal of Nanomedicine; 2014: 9 3551-3565.

[5] Bulent, U., Turkdemir, M. H., Cicek, A and Mete, A. (2015). Role of irradiation in the green synthesis of silver nanoparticles mediated by fig (Ficus carica) leaf extract. Spectrochim Acta Part A Mol Biomol Spectrosc; 135: 153161.

[6] Siddiqi, K. S., Husen, A., Rao, R. A. K. (2018). A review on biosynthesis of silver nanoparticles and their biocidal properties. J Nanobiotechnol; 16: 14.

[7] Karar, M. G and Kuhnert, N. (2017). Herbal drugs from Sudan Traditional uses and phytoconstituents. Pharmacognosy reviews; 11 (22): 83.

[8] Abdeen, S., Isaac, R. R., Geo, S., Sornalekshmi, S., Rose, A and Praseetha, P. K. (2013). Evaluation of Antimicrobial Activity of Biosynthesized Iron and Silver Nanoparticles Using the Fungi Fusarium Oxysporum and Actinomycetes sp. on Human Pathogens. Nano Biomedicine \& Engineering; 1; 5 (1).

[9] Mahfuzul Hoque, M. D., Bari, M. L., Inatsu, Y., Juneja, V. K. and Kawamoto, S. (2007). Antibacterial activity of guava (Psidium guajava L. ) and neem (Azadirachta indica A. Juss. ) extracts against foodborne pathogens and spoilage bacteria. Foodborne pathogens and disease. Dec 1; 4 (4): 481-8.

[10] Veerasamy, R., Xin, T. Z., Gunasagaran, S., Xiang, T. F., Yang, E. F., Jeyakumar, N. and Dhanaraj, S. A. (2011). Biosynthesis of silver nanoparticles using mangosteen leaf extract and evaluation of their antimicrobial activities. Journal of Saudi Chemical Society; $1 ; 15$ (2): 113-20.

[11] Vijayakumar, M., Priya, K., Nancy, F. T., Noorlidah, A. and Ahmed, A. B. A. (2013). Biosynthesis, characterisation and anti-bacterial effect of plant-mediated silver nanoparticles using Artemisia nilagirica. Industrial Crops and Products, 41, 235-240.

[12] Bindhu, M. R., \&Umadevi, M. (2013). Synthesis of monodispersed silver nanoparticles using Hibiscus cannabinus leaf extract and its antimicrobial activity. Spectrochimica Acta Part A: Molecular and Biomolecular Spectroscopy, 101, 184190. 